\title{
Development of Multi-Objective Optimization Model for Electromagnetic Die Forming of Aa5083 Aluminum Alloy Sheet
}

\author{
Prabhu.L, Sangeetha Krishnamoorthi, Raja Krishnan, Thahir .C, Sreeraj S Menon
}

\begin{abstract}
Electromagnetic die forming is a high-speed formation method that can be quite effective in increasing the limits on the shape of the metal sheet of low weight and of the strong electrical conductivity content. A coil is an essential instrument for transmitting electrical power to plastic energy, and the geometry of the coil plays a key role in macrofield transmission. Experiments of the electrical composition of 0.5 $\mathrm{mm}, 0.7 \mathrm{~mm}$ and $0.9 \mathrm{~mm}$ AA5083 aluminum sheets are performed via the box-behnken technique with a single layer spiral and a flat square-cross section and spiral. Evaluating characteristics like total height, rib height internal diameter, and external diameter for various charge voltage and current was investigated for the forming behaviour. The results show that the efficiency of production is very dependent on the divide and thickness of work pieces.
\end{abstract}

Keywords : Electromagnetic die forming, AA5083 Aluminium alloy, circular coil, working gap, Microstructure.

\section{INTRODUCTION}

Electromagnetic die forming (EMF) is high speed technique used in the forming of the spindle and the sheet by magnetic repulsive forces. Due to the extremely high deformation rate and the resulting effect, formability has been improved and the back of the spring decreased compared to conventional quasi-static methods. Furthermore, the contact-free use of power reduces the need for male punching and lubrication, significantly reducing costs. EMF can be used to create complicated objects, such as a protrusion of a deep-drawn channel on the side wall that with traditional punching processes cannot be created. EMF uses in the automobile machinery, aerospace and other

Revised Manuscript Received on December 16, 2019

* Correspondence Author

Prof.L.Prabhu*, Assoc. Professor Department of Mechanical Engineering Aarupadai Veedu Institute of Technology Vinayaka Mission Research Foundation, Chennai, India, Email: prabhu@avit.ac.in

Sangeetha Krishnamoorthi, Sangeetha Krishnamoorthi, Associate Professor, Department of Mechanical Engineering Aarupadai Veedu Institute of Technology Vinayaka Mission Research Foundation, Chennai, India. sangeethas@avit.ac.in

Raja Krishnan, PG Student, Department of Mechanical Engineering, Aarupadai Veedu Institute of Technology, Vinayaka Mission Research Foundation, Chennai, India.

Thahir.C, UG Student, Department of Mechanical Engineering, Aarupadai Veedu Institute of Technology, Vinayaka Mission Research Foundation, Chennai, India.

Sreeraj S Menon, UG Student, Department of Mechanical Engineering, Aarupadai Veedu Institute of Technology, Vinayaka Mission Research Foundation, Chennai, India sectors have recently increased because of its effectiveness in the shaping of low-deformance sheet metals, such as aluminum sheet in [1]. The time variation currents passed through the work spiral produce eddy current without mechanical or working media in the workpiece [2]. EMF can be used successfully for shaping complex structures, with increased strength and minimized screwing benefits states[3]. The free formation and cavity filling formulation of aluminum alloy layer was proposed in [4]. We researched the impact of die geometry, tension frequency and failure position and reported that increased release energy results in an increased cavity filling and stress level. In [5]investigated the efficacy and formability of $\mathrm{Mg}$ Alloy Blades through bulging experiments through warm-based electromagnetic-hybrid-forming (WEMF) voltage, capacity and temperature effects. The findings of research to study the reduction of a $20 \mathrm{~mm}$ diameter to $5 \mathrm{~mm}$ of a AA $57541 \mathrm{~mm}$ sheet by traditional metal forging (stamping) and EMF by the use of modern metal forging (stamping) and have been defined in [6] engineered an electrical two-stage formation (EMF) of a sheet metal in the shape of a middle frame. a parallel row covering the work surface uniformly by means of magnetically pressurized magnetic force. In [7] the basis of conceptual analyzes of coil inducting ratios, sheet thickness and energy efficiency, suggested the new Flat Spiral coil for large and spacious plates[8]. We also reported that, thanks to an additional influence of each layer of the multi-layer coils, the magnet power working on the workpiece simply rises, while the tension on the coils can be effectively controlled due to the share in each layer of multi-layer coils[9]. The magnetism works on the workpiece. ANSYS simulated the electromagnetic force and plastic sheet deformation with electromagnetic force at different temperatures on a new method of controlling the distortion of welding with trailing electromagnetic force[10].In [11]-[12] Electromagnetic blank Restrainer (EMBR) is a new technology that has recently been developed to monitor product motions in sheet metal forming processes. EMBR's inherent feature is a magnetic attraction on the ferrous plates. In this work, a single-layer spiral, flat spiral coil with square cross section was formed to form AA5083 aluminum alloy plates. This investigation has taken into consideration process parameters such as voltage, gap and thickness of the workpiece. In comparison to the proportion of error deviation, the measured and 
predicted shape of the part was identified. Mechanical tests are carried out in the forming zone to assess the strength of the material. In addition, the EMDF method optimization parameters study was conducted to define the optimum system parameters through the Box benken technique. In the process, the microstructure study were undertaken to analyze surface features at area creation.

\section{MATERIALS AND METHODS}

The configuration of the EMDF system coil as shown in the Fig. 1.The coil has an inner and external $20 \mathrm{~mm}$ and a $120 \mathrm{~mm}$ square cross section from $6 \times 6 \mathrm{~mm}$ There is a distance of $2.5 \mathrm{~mm}$ between the spools and a spiral total of 6 . The space between the bobbins was filled with epoxy resin and araldihyde so as to restrict the interaction between the spindles and preserve the distance between the coils and to avoid intermediate changes during current flow in the coil.

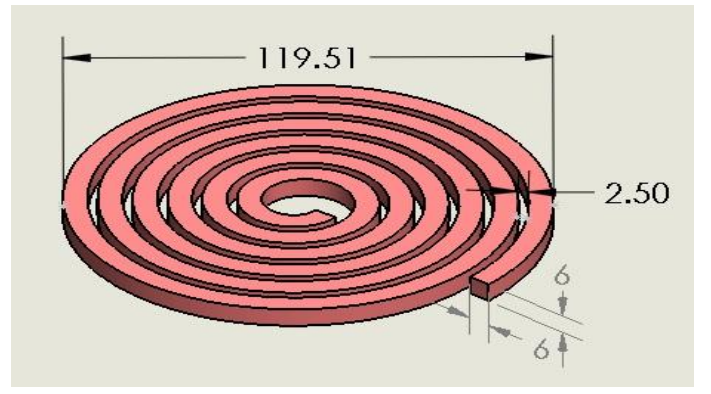

Fig. 1.Coil design for EMDF process.

The workpiece material is AA5083 aluminum alloy. Image. 3Displays the die for electrical formation. The working-piece, belt and die are mounted on the circular sleeve, the bob is attached to the center of the upright mounting seat, and the workpiece is placed between the die and bobbin positioned in coaxial position with the bobbin. For tests, a power supply with a maximum capacity for energy of $10 \mathrm{~kJ}$ is used. Fig. 2 shows the schematic view of die with dimensions.Table-I Displays the electromagnetic machine forming specifications. In the process of forming the Gauss counter, the magnetic stream formed in the coil is determined and the gauss meter parameters are displayed in a Table-II.

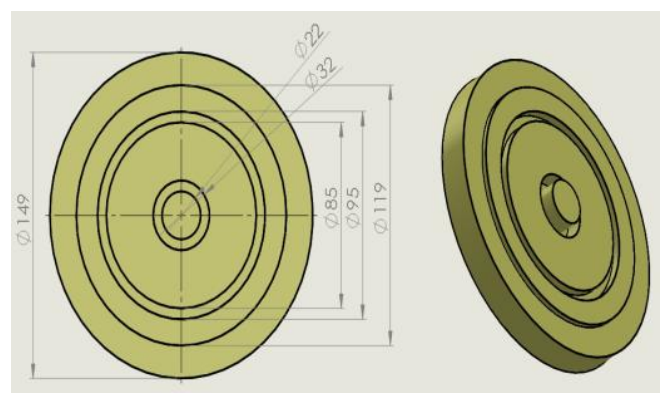

Fig. 2.Schematic view of Die with dimensions.

Table- I: Electromagnetic forming machine specifications

\begin{tabular}{|l|l|}
\hline Parameters & Specifications \\
\hline Energy capacitor & $10 \mathrm{~kJ} ; 2000 \mathrm{~V}$ \\
\hline
\end{tabular}

\begin{tabular}{|l|l|}
\hline DC Discharge Unit & $50 \mathrm{KA}$ \\
\hline Transformer & $10-15 \mathrm{KVA}$ \\
\hline $\begin{array}{l}\text { Discharge thyristor } \\
\text { module }\end{array}$ & 3000 PIE 20000 Arm \\
\hline Thyristor type & $\begin{array}{l}\text { Firing and AC variable thyristor } \\
\text { control module with HMI and PLC }\end{array}$ \\
\hline
\end{tabular}

Table- II: Gauss meter specifications

\begin{tabular}{|l|l|l|l|}
\hline Parameters & Low & Medium & High \\
\hline Voltage & DC 500V & DC 800V & DC 1250V \\
\hline Current & $\begin{array}{l}80,000 \\
\text { pulse } \\
\text { current }\end{array}$ & $\begin{array}{l}1,30,000 \\
\text { pulse } \\
\text { current }\end{array}$ & $\begin{array}{l}2,00,000 \\
\text { pulse current }\end{array}$ \\
\hline
\end{tabular}

An EMDF system consists, as shown schematically, of a condenser desk, a charging tool, a high speed toggle, bobble, mounting and workpiece. The energy deposited on the condenser bank is dissipated and the loop is running with a resonant current. A magnetic field entering the workpiece is produced by an electrical current flowing through the coil. The changing period magnetic field causes electric currents in its change in the workpiece, which move in the opposite direction towards the surface of the coil current. The coil and workpiece resist each other due to the presence of the magnetic fields or similar, according to the existing Lorentz power. In most cases the spindle is fixed so that the workpiece moves away from the spindle. The workpiece is shaped in the specified die shape based on the restrictions imposed by devices such as the die and the holder.

Box-Behnken has been used to administer the necessary number of tests as shown in the table. The development of Box-Behnken is an isolated quadratic system that does not include an embedded factorial or factorial design. The treatment combinations in this design are at the center and the middle ends of the process space. These designs can be rotated (or almost rotated) and require 3 factor levels. The Box-Behnken design offers the highest efficiency for an experiment with three factors and 3 levels; in addition, comparing a central composite design, the number of experiments is much smaller. Box-Behnken is an unoptimized three-level rotatable second-order model. This is a different 3-level model since it has no points at the vertices of the test region. This can be useful if the points at the corners of the cube reflect grades that are unfavorably costly or untestable due to physical system constraints. Fig. 3 shows the Experimental setup of EMDF machine. 


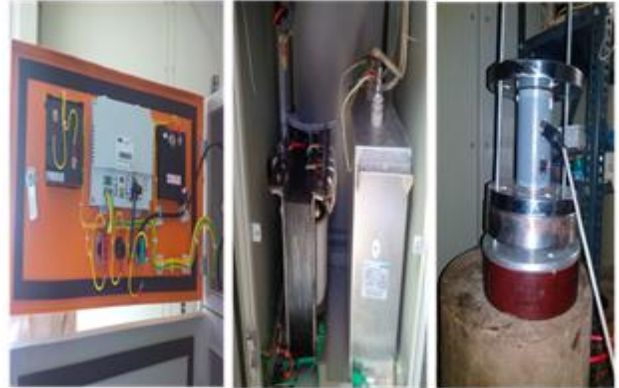

Fig. 3.Experimental setup of EMDF machine.

Table-III describes the AA5083 aluminum alloy material, chemical composition. Table IV illustrates the Parameters and their selected levels of EMF Process.

Table- III: AA5083 aluminum alloy material, chemical composition.

\begin{tabular}{lllllllll}
\hline $\mathrm{Si}$ & $\mathrm{Fe}$ & $\mathrm{Cu}$ & $\mathrm{Mn}$ & $\mathrm{Mg}$ & $\mathrm{Zn}$ & $\mathrm{Ti}$ & $\mathrm{Cr}$ & $\mathrm{A} 1$ \\
\hline 0.4 & 0.4 & 0.1 & $0.4-$ & $4.0-$ & 0.25 & 0.15 & $0.05-$ & Balance \\
& & & 1.0 & 4.9 & & & 0.25 & \\
\hline
\end{tabular}

Table- IV: Parameters and their selected levels of EMF

\begin{tabular}{llllll}
\multicolumn{5}{c}{ Process. } \\
\hline \multicolumn{1}{c}{ Parameters } & -2 & -1 & 0 & 1 & 2 \\
\hline & 2 & 5 & 10 & 15 & 20 \\
\hline $\begin{array}{l}\text { A Working gap } \\
(\mathrm{mm})\end{array}$ & & & & & \\
B Voltage (V) & 200 & 500 & 800 & 1100 & 1400 \\
C Workpiece & 0.3 & 0.5 & 0.7 & 0.9 & 1.1 \\
$\quad$ thickness (t) & & & & & \\
\hline
\end{tabular}

The multiple response functions, such as Outer diameter, Inner diameter, Rib height and Total height are the function of working gap, voltage, current count and workpiece thickness. The response function can be expressed as $Y=f(A$, $\mathrm{B}, \mathrm{C}) \mathrm{The}$ second order polynomial formula for the answer $\mathrm{Y}$ is given in the Eq. (2)

$\mathrm{Y}=\mathrm{b}_{0}+\sum \mathrm{b}_{\mathrm{i}} \mathrm{X}_{\mathrm{i}}+\mathrm{b}_{\mathrm{ii}} \mathrm{X}_{\mathrm{i}}^{2}+\mathrm{b}_{\mathrm{ii}} \mathrm{X}_{\mathrm{i}} \mathrm{X}_{\mathrm{j}} \ldots$

Table- V: Parameters and their selected levels of EMF Process.

$\begin{array}{ccccccc}\text { Voltage } & \begin{array}{c}\text { Working } \\ \text { gap } \\ \text { ( }\end{array} & \begin{array}{c}\text { Workpiece } \\ \text { thickness }\end{array} & \text { ID } & \text { OD } & \mathrm{RH} & \mathrm{TH} \\ \text { (t) } & \mathrm{mm} & \mathrm{mm} & \mathrm{Mm} & \mathrm{mm} \\ 500 & 10 & 0.9 & 27.5 & 101.4 & 4 & 3.7 \\ 1100 & 15 & 0.7 & 29.4 & 99.5 & 3.81 & 3.94 \\ 500 & 10 & 0.5 & 28.1 & 100.4 & 3.94 & 4.11 \\ 500 & 5 & 0.7 & 28.7 & 99.8 & 4.15 & 4.27 \\ 800 & 15 & 0.5 & 29.2 & 98.9 & 4.2 & 4.16 \\ 1100 & 10 & 0.9 & 32.5 & 98.4 & 3.84 & 4.07 \\ 800 & 15 & 0.9 & 27.1 & 103.5 & 3.3 & 3.42 \\ 800 & 5 & 0.5 & 31.52 & 96.4 & 4.67 & 5.23 \\ 1100 & 5 & 0.7 & 31.4 & 96.8 & 4.4 & 4.91 \\ 1100 & 10 & 0.5 & 30.65 & 97.4 & 4.47 & 4.84 \\ 800 & 10 & 0.7 & 29.5 & 98.2 & 4.25 & 4.61 \\ 800 & 5 & 0.9 & 30.1 & 98.1 & 4.2 & 4.14 \\ 500 & 15 & 0.7 & 26.7 & 102.5 & 3.51 & 3.47\end{array}$

Table-V illustrates Parameters and their selected levels of EMF Process. Each The mathematical equation representing the Outer diameter, Inner diameter, Rib height and Total height is given in Eq. (3), (4), (5) and (6).Regression Equation from RSM.

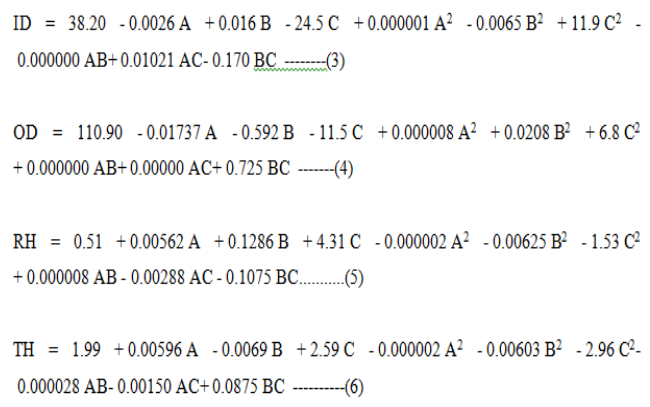

\section{EXAMINING ADEQUACY OF THE DEVELOPED MODEL}

Use the ANOVA method to evaluate the adequacy of the built model. With this technique the model shall be deemed to be adequate within the confidence limit if the calculated value of the Fratioof the model developed does not exceed the standard tabulated value of the Fratio for the required confidence level (say 99 percent). Table shows the results of the ANOVA are sufficient which are inferred by Table VI, Table VII, Table VIII and Table IX. Determination coefficient explains how well the data corresponds to the model established. The evaluation method is a statistical measure of the estimation of the actual data points by the regression line. In this scenario, the decision coefficient $(\mathrm{R} 2)=0.95$ means that the model does not clarify just $5 \%$ of the total variations.

Table- VI: ANOVA table for Inner diameter .

\begin{tabular}{lllllll}
\hline Source & DF & Adj SS & Adj MS & $\begin{array}{l}\text { F- } \\
\text { Value }\end{array}$ & $\begin{array}{l}\text { P- } \\
\text { Value }\end{array}$ \\
\hline Model & 9 & 35.064 & 3.896 & 5.09 & 0.044 & Significant \\
A & 1 & 20.9628 & 20.9628 & 27.39 & 0.003 & \\
B & 1 & 10.8578 & 10.8578 & 14.19 & 0.013 & \\
C & 1 & 0.6441 & 0.6441 & 0.84 & 0.401 & \\
Square & 3 & 0.9831 & 0.3277 & 0.43 & 0.742 & \\
2-Way Interaction & 3 & 1.6162 & 0.5387 & 0.7 & 0.589 & \\
Error & 5 & 3.8264 & 0.7653 & & & \\
Lack-of-Fit & 3 & 3.6397 & 1.2132 & 13 & 0.072 & Non-Significant \\
Pure Error & 2 & 0.1867 & 0.0933 & & & \\
Total & 14 & 38.8904 & & & & \\
\hline
\end{tabular}

Table- VII: ANOVA table for Outer diameter.

\begin{tabular}{lllllll}
\hline Source & DF & Adj SS & Adj MS & $\begin{array}{l}\text { F- } \\
\text { Value }\end{array}$ & P-Value & \\
\hline Model & 9 & 53.5502 & 5.95 & 9.36 & $0.012<0.05$ & Significant \\
A & 1 & 18 & 18 & 28.31 & 0.003 & \\
B & 1 & 22.1112 & 22.1112 & 34.78 & 0.002 & \\
C & 1 & 8.6112 & 8.6112 & 13.54 & 0.014 & \\
Square & 3 & 2.7252 & 0.9084 & 1.43 & 0.339 & \\
2-Way Interaction & 3 & 2.1025 & 0.7008 & 1.1 & 0.43 & \\
Error & 5 & 3.1792 & 0.6358 & & & Significant \\
Lack-of-Fit & 3 & 3.0925 & 1.0308 & 23.79 & $0.041<0.05$ & \\
Pure Error & 2 & 0.0867 & 0.0433 & & & \\
Total & 14 & 56.7293 & & & & \\
\hline & & & & & & \\
\end{tabular}

Table- VIII: ANOVA table for 


\begin{tabular}{lllllll}
\multicolumn{7}{c}{ Rib height. } \\
\hline Source & DF & Adj SS & Adj MS & F-Value & P-Value & \\
\hline Model & 9 & 1.79507 & 0.199453 & 10.64 & $0.009<0.05$ & Significant \\
Linear & 3 & 1.42125 & 0.47375 & 25.28 & 0.002 & \\
A & 1 & 0.1058 & 0.1058 & 5.65 & 0.063 & \\
B & 1 & 0.845 & 0.845 & 45.09 & 0.001 & \\
C & 1 & 0.47045 & 0.47045 & 25.1 & 0.004 & \\
Square & 3 & 0.20795 & 0.069316 & 3.7 & 0.097 & \\
2-Way Interaction & 3 & 0.16588 & 0.055292 & 2.95 & 0.137 & \\
Error & 5 & 0.0937 & 0.01874 & & & \\
Lack-of-Fit & 3 & 0.0865 & 0.028833 & 8.01 & 0.113 & Non- \\
& & & & & & significant \\
Pure Error & 2 & 0.0072 & 0.0036 & & & \\
Total & 14 & 1.88877 & & & & \\
\hline
\end{tabular}

Table- VIII: ANOVA table for total height.

\begin{tabular}{lllllll}
\hline Source & DF & Adj SS & Adj MS & F-Value & P-Value & \\
\hline Model & 9 & 3.6573 & 0.40637 & 26.27 & $0.001<0.05$ & Significant \\
Linear & 3 & 3.32723 & 1.10908 & 71.7 & 0 & \\
A & 1 & 0.61051 & 0.61051 & 39.47 & 0.002 & \\
B & 1 & 1.5842 & 1.5842 & 102.42 & 0 & \\
C & 1 & 1.13251 & 1.13251 & 73.21 & 0 & \\
Square & 3 & 0.25982 & 0.08661 & 5.6 & 0.047 & \\
2-Way Interaction & 3 & 0.07025 & 0.02342 & 1.51 & 0.319 & \\
Error & 5 & 0.07734 & 0.01547 & & & \\
Lack-of-Fit & 3 & 0.05288 & 0.01763 & 1.44 & 0.435 & Non- \\
& & & & & & significant \\
Pure Error & 2 & 0.02447 & 0.01223 & & & \\
Total & 14 & 3.73464 & & & & \\
& & & & & &
\end{tabular}

The normal probability plot was developed to understand whether normality exists in the experimental data. The residuals of the measured experiment against the resulting residue of the standard normal distribution are added to the usual likelihood path. If the graph indicates a straight line, the detected specimen may reasonably be assumed to come from a normal distribution. The usual likelihood plot drawn shows that the data are distributed naturally. Figure. 5 shows that the residuals fall on the line, so the errors are normally distributed.

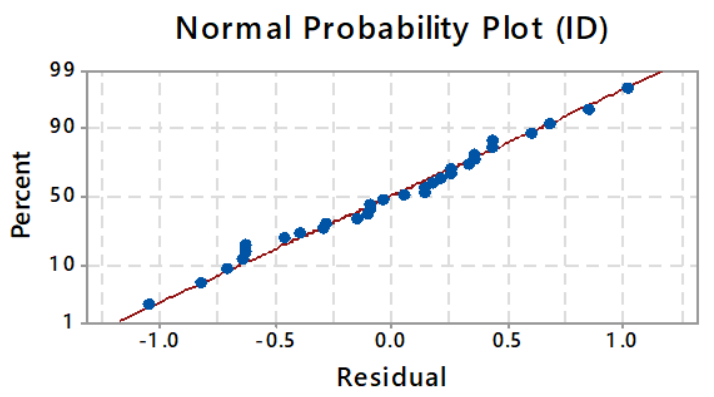

a)

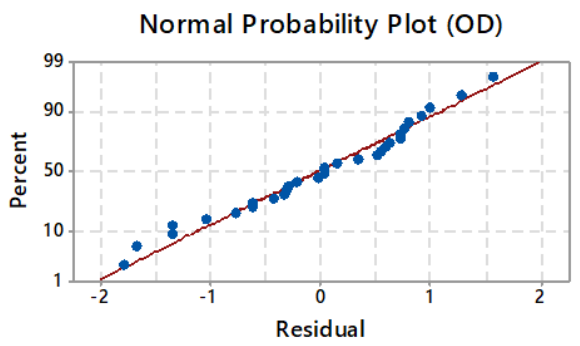

b)
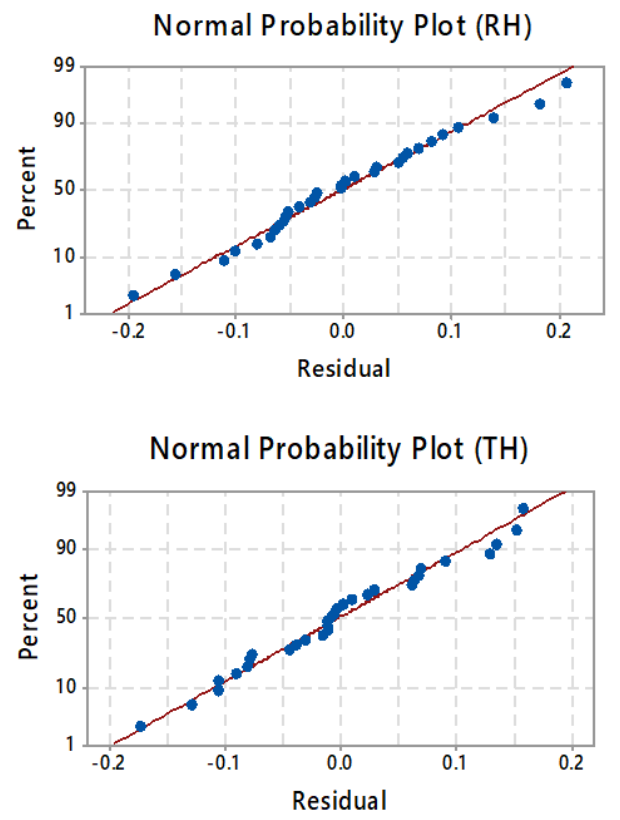

c)

Fig. 4.Normal probability plot for a)ID,b) OD, c)TH.

Fig. 4 shows the performance of Normal probability for ID,OD, TH.

\section{RESULT AND DISCUSSION}

A spiral-flat single coil layer with a square electromagnetic shaping cross section is designed to achieve a winding divide of $2,5 \mathrm{~mm}$ between the spiral. The blank holder force in the experiment remained constant and the voltage of discharge is $2 \mathrm{kV}$. It demonstrates that during high-velocity electromagnetic forming the major influence of magnetic force deformation characteristics is the size and distribution, although the effect of friction on electromagnetic high-velocity formation is minimal. Fig.5. Shows after forming the final component. The experimental fitness value is observed in fig. 6 to be slightly less than expected, but the maximum difference is only about $0.3 \mathrm{~mm}$ and the fitability error is less than 10 percent. A fitability comparison shows that the electrical coil constructed to create more precise parts without scratching the surfaces.

Experimental workpiece profiles can be assessed by 3D measurement engineering (Projector Model, TII Techno Testing's, Chennai). 3D measuring technology is an important reverse engineering approach, and 3D profile measurement technology can accurately measure the curved surface of the forming 
components. Fitness of the formed workpiece can then be obtained by fitting the die surface and illustrated in Fig. 7 the fitness of the formed workpieces. The figure shows that some portion of the sheet to match with the die is still some way from the mounting. Fig. 8 shows Z-axis along the A-A line.

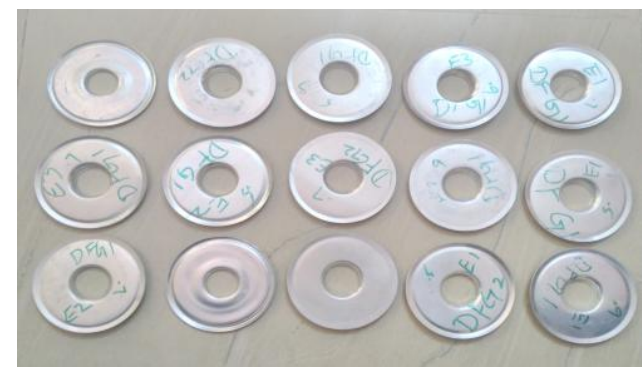

Fig. 5. EMDF workpiece.

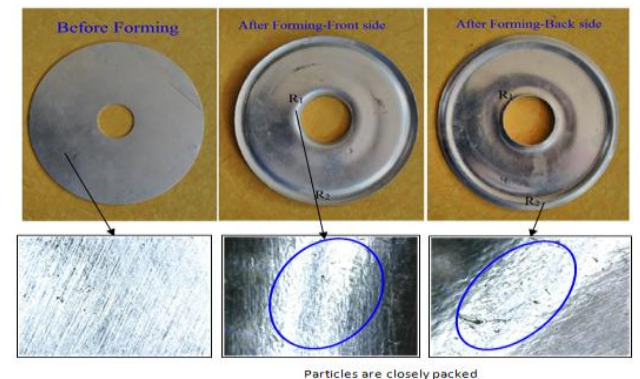

Fig. 6.Workpiece before forming and after forming. R1, R2Forming region .

Table- X: ANOVA table for Rib height.

\begin{tabular}{lllllll}
\hline BHN before forming & \multicolumn{5}{l}{ Brinell hardness after forming (BHN) } \\
\cline { 2 - 7 } & $\mathrm{t}-0.5 \mathrm{~mm}$ & $\mathrm{t}-0.7 \mathrm{~mm}$ & $\mathrm{t}-0.9 \mathrm{~mm}$ \\
\hline & $\mathrm{R} 1$ & $\mathrm{R} 2$ & $\mathrm{R} 1$ & $\mathrm{R} 2$ & $\mathrm{R} 1$ & $\mathrm{R} 2$ \\
\hline $\mathbf{5 2}$ & 57.4 & 56.8 & 57.2 & 56.4 & 56.7 & 56.2 \\
$\mathbf{5 2}$ & 57.2 & 56.5 & 56.9 & 55.8 & 56.5 & 55.4 \\
$\mathbf{5 2}$ & 57 & 56.4 & 56.3 & 55.4 & 56.2 & 55.1
\end{tabular}

${ }^{*}$ - workpiece thickness, $R_{1}, R_{2}$-Region

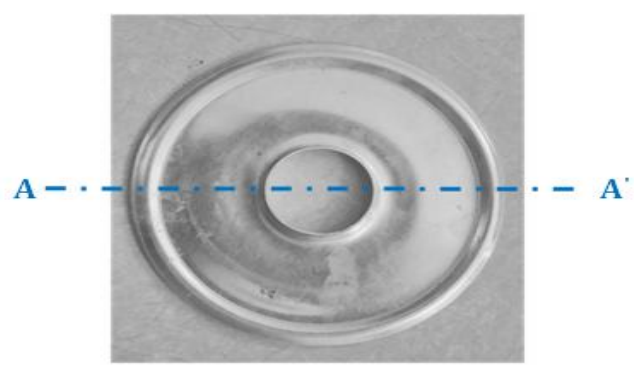

Fig. 7.Experimental results at $5 \mathrm{~mm}$ working gap .

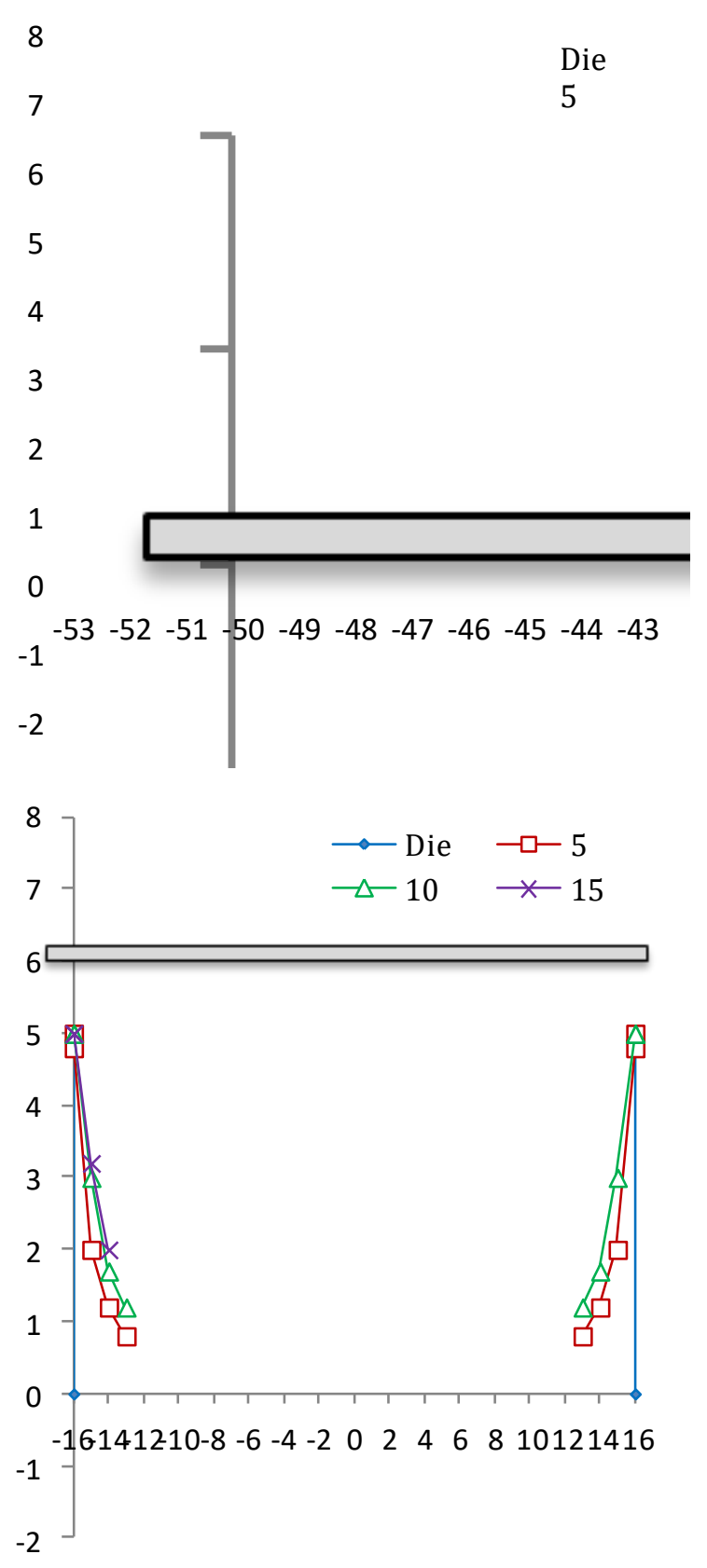


8

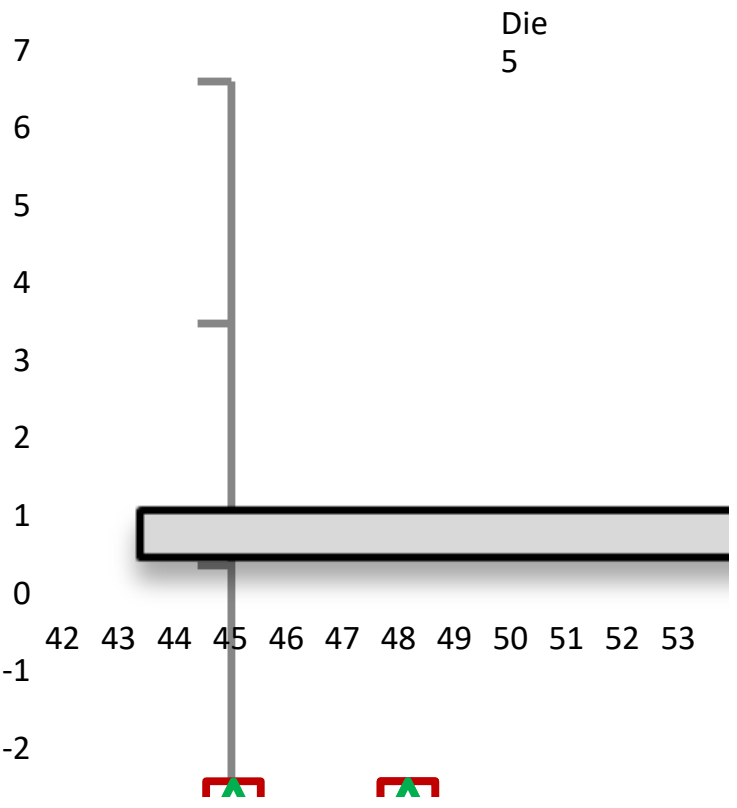

Fig. 8. Z-axis along the A-A line .

Hardness test was carried out as per ASTM E-384 standard for the electromagnetic formed specimens by HV-115 Vickers hardness testing machine. A small piece of sample was taken from the workpiece to evaluate the hardness of the specimen at the forming region. A test was carried out in the room temperature and the applied load of $40 \mathrm{kgf}$. The hardness test results are shown in Table. X. An average hardness of 55 to $57 \mathrm{HV}$ was achieved at various working gap between $5 \mathrm{~mm}$ and $15 \mathrm{~mm}$, voltage between 500 $\mathrm{V}$ to $1100 \mathrm{~V}$ and workpiece thickness $0.5 \mathrm{~mm}$ to $0.9 \mathrm{~mm}$. It is observed from that maximum hardness of $57.4 \mathrm{HV}$ was achieved when working gap $5 \mathrm{~mm}$, voltage of $1100 \mathrm{~V}$ and workpiece thickness $0.5 \mathrm{~mm}$.

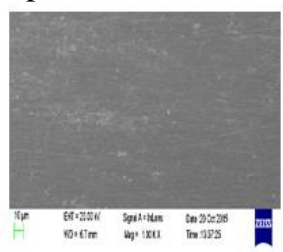

a)

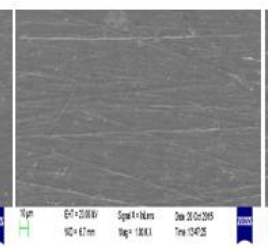

b)

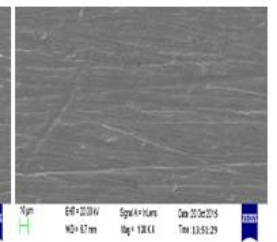

c)
Fig. 9.Deformed sample @ working gap $5 \mathrm{~mm}$ and material thickness of (a) $0.5 \mathrm{~mm}$, (b) $0.7 \mathrm{~mm}$ and (c) $0.9 \mathrm{~mm}$.

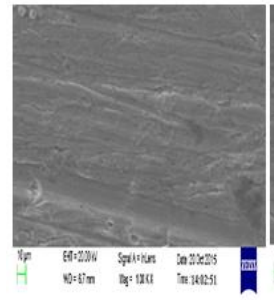

a)

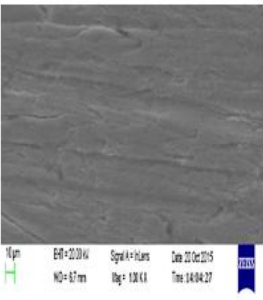

b)

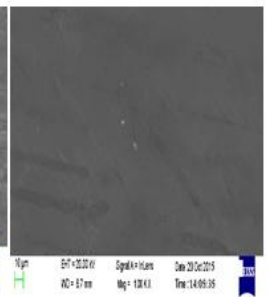

c)
Fig. 10. Deformed sample @ working gap $10 \mathrm{~mm}$ and material thickness of (a) $0.5 \mathrm{~mm}$, (b) $0.7 \mathrm{~mm}$ and (c) $0.9 \mathrm{~mm}$
The microstructure of the workpiece at the forming region was examined with aid of SEM (Carl Zeiss SUPRA-55, centre for nano science and nanotechnology laboratory, Chennai) to observe the surface texture characteristics of the workpiece. Fig. 9 and 10 shows the microstructure of formed workpiece at a working gap of $5 \mathrm{~mm}$ and $10 \mathrm{~mm}$ with different material thickness $0.5 \mathrm{~mm}, 07 \mathrm{~mm}$ and $0.9 \mathrm{~mm}$. The molecules were tightly bonded in $0.5 \mathrm{~mm}$ thickness workpiece and hence, finer surface finish was observed. Further increase in workpiece thickness, hardness of the material gets decreased. Because of the higher specimen thickness and higher working gap it opposes forming stress against the electromagnetic force created by the coil.

The RSM optimization method has been used to refine EMF system parameters. The optimisation desirability for the entire process was calculated to demonstrate the feasibility of optimisation, i.e. to explore whether or not all parameters are within its operational range. The goal was to assess the outer length, inner size, rib height and overall height. The optimal composite rate is 0.9533 and the system parameters are correctly accepted.

Data analysis performed the verification experiment with the optimal control variables. It is basically a verification or invalidation of optimal control factors grades. The unsatisfactory study includes the need for further studies.

Table- XI: Displays the results and the values of the experiments. It was observed that the percentage of errors in both the performance response characteristics was within the acceptable limits of \pm 10 percent. This was in good agreement between the expected machining capability and the real machining output for the tests.

Table- XI: Confirmation test .

\begin{tabular}{llllllllllll}
\hline WG & V & WT & ID & \multicolumn{3}{c}{ OD } & \multicolumn{3}{c}{ RH } & \multicolumn{3}{c}{ TH } \\
\cline { 5 - 12 } & & & & Exp & Predicted & Exp & Predicted & Exp & Predicted & Exp & Predicted \\
\cline { 4 - 12 } & 1100 & 0.7 & 30.81 & 31.528 & 96.654 & 97.331 & 4.53 & 4.6004 & 4.891 & 5.0004 \\
$\mathbf{5}$ & 1100 & 0.7 & 30.24 & 31.528 & 96.812 & 97.331 & 4.46 & 4.6004 & 5.268 & 5.0004 \\
$\mathbf{5}$ & 1100 & 0.7 & 30.69 & 31.528 & 96.457 & 97.331 & 4.41 & 4.6004 & 5.314 & 5.0004 \\
\hline
\end{tabular}

\section{CONCLUSION}

Electromagnetic die formation method has been experimentally studied in the creation of an aluminum sheet. A flatspiral coil of one layer of copper was designed on a lorentz power. The results are as follows.

Increased the voltage applied to the spindle from 500 to $1100 \mathrm{~V}$, the induced EMF increases, which is more formable. The workpiece, which provides improved formability, can extract a high level of EMF strength while decreasing the working gap. Contrary to this argument, voltage decreases and work space improvements appear to be insufficient.

The working gap has a major effect on driving coil's energy efficiency, and minimizing the working distance increases magnetic strength on the plate, which can increase the sheet's plastic flow.

In fact, a Box-behnken technique optimization study

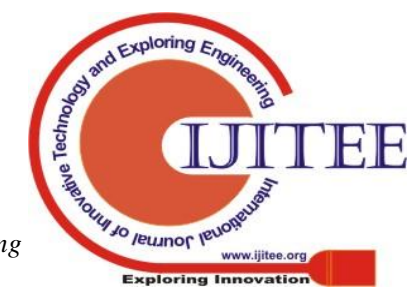


was conducted to define the optimum system parameters to achieve better shape. Working distance, voltage and workpiece thickness are respectively 5, 1100 and $0.7 \mathrm{~mm}$ with optimum system parameters.

\section{REFERENCES}

1. V. Psyk ,D. Risch ,B. L. Kinsey ,A. E. Tekkaya,M. Kleiner," Electromagnetic forming-a review", Journal of Materials Processing Technology,Vol.11,No.5,May .2011,pp.787-829.

2. Y. V. Batygin, S. F. Golovashchenko ,A. V. Gnatov ," Pulsed electromagnetic attraction of sheet metals-fundamentals and perspective applications", Journal of Materials Processing Technology,Vol.213,No.3,Mar.2013,pp.444-52.

3. J. M. Imbert,S. L. Winkler ,M. J. Worswick, S. Golovashchenko," Formability and damage in electromagnetically formed AA5754 and AA6111", International Conference on High Speed Forming, 2004,pp. 201-210.

4. Z. Meng ,S. Huang ,J. Hu ,W. Huang ,Z. Xia,” Effects of process parameters on warm and electromagnetic hybrid forming of magnesium alloy sheets", Journal of Materials Processing Technology, Vol.211.No.5,May.2011,pp.863-7.

5. J. Imbert ,M. Worswick," Reduction of a pre-formed radius in aluminium sheet using electromagnetic and conventional forming", Journal of Materials Processing Technology,Vol.212,No.9,Sep.2012,pp.1963-72.

6. J. Imbert,M. Worswick, " Reduction of a pre-formed radius in aluminium sheet using electromagnetic and conventional forming", Journal of Materials Processing Technology,Vol.212.No.9,Sep.2012,pp.1963-72.

7. J. H. Kim ,D. Kim ,M. G. Lee, "Experimental and numerical analysis of a rectangular helical coil actuator for electromagnetic bulging", International Journal of Advanced Manufacturing Technology,May.2015,Vol.78,No.5-8,pp.825-39.

8. H. G. Noh ,W. J. Song, B. S.Kang ,J. Kim,” Two-step electromagnetic forming process using spiral forming coils to deform sheet metal in a middle-block die", International Journal of Advanced Manufacturing TechnologyVol.76,No.(9-12),Feb.2015,pp.1691-703.

9. D. A. Oliveira,M. J. Worswick ,M. Finn ,D. Newman D. "Electromagnetic forming of aluminum alloy sheet: free-form and cavity fill experiments and model", Journal of Materials Processing Technology, Vol.170,No.(1-2),Dec.2005,pp.350-62.

10. W. Luo ,L. Huang ,J. Li ,X. Liu ,Z. Wang," A novel multi-layer coil for a large and thick-walled component by electromagnetic forming", Journal of Materials Processing Technology,Vol.214,No.11,Nov.2014,pp.2811-9.

11. X. Wei, L. Xuesong ,Y. Jianguo ,F. Hongyuan ,X. Wenli," Effect of temperature on plastic deformation of sheet by electromagnetic force. journal of materials processing technology"Vol.209,No.5,Mar.2009,pp.2693-8.

12. Y. R. Seo ," Electromagnetic blank restrainer in sheet metal forming processes", International Journal of Mechanical Sciences, Vol.50,No.4,Apr.2008,pp.743-51.

\section{AUTHORS PROFILE}

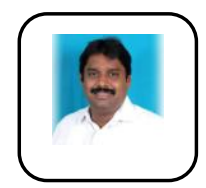

L.Prabhu, Assoc. Professor Department of Mechanical Engineering Aarupadai Veedu Institute of Technology Vinayaka Mission Research Foundation prabhu@avit.ac.in

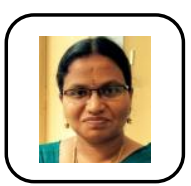

Sangeetha Krishnamoorthi, Associate Professor, Department of Mechanical Engineering Aarupadai Veedu Institute of Technology Vinayaka Mission Research Foundation sangeethas@avit.ac.in.

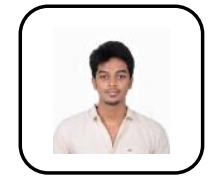

Raja Krishnan, PG Student,Department of Mechanical Engineering, Aarupadai Veedu Institute of Technology, Vinayaka Mission Research Foundation.

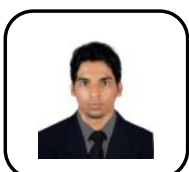

Thahir.C, UG Student,Department of Mechanical Engineering, Aarupadai Veedu Institute of Technology,

Vinayaka Mission Research Foundation.

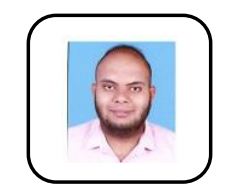

Sreeraj S Menon, UG Student, Department of Mechanical Engineering, Aarupadai Veedu Institute of Technology, Vinayaka Mission Research Foundation. 